Background: Scientific interest in the clinical aspects surrounding vitamin $D$ has increased exponentially in recent years. Unfortunately, this interest is not currently associated with a proportional level of consensus. Indeed, the large number of studies in this field, which are often of low quality and secondary importance has confused even experts and driven them towards controversial positions.

Objectives: To shed light on this topic, we arranged a meeting with the aim of collecting the opinions of 50 experts in different specialties (" $D$. Battito Group"), including internists, endocrinologists, rheumatologists, pediatricians, geriatricians, dermatologists, gynecologists and nephrologists. This meeting dealt with specific questions regarding the management of hypovitaminosis D and aimed to investigate the opinions of Italian experts on this topic. Six key questions were addressed in the meeting. Methods: After a short lecture and a 30 minutes discussion, all the experts expressed their opinions, which were recorded together with any specific commentary.

Results: The results of the meeting demonstrated the presence of insufficient agreement on many key questions regarding the management of vitamin $\mathrm{D}$ deficiency, even among clinical experts.
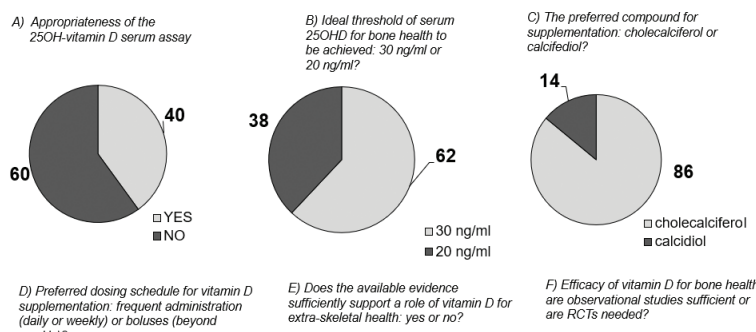$$
\text { wooky)? }
$$
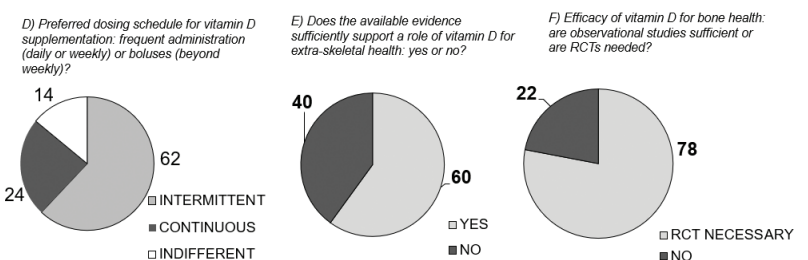

$\square$ NO
Conclusion: We hope that the various scientific societies will recognize and analyze the inconsistencies in their own positions and reach adequate consensus, especially on the tenets required for conducting proper and useful investigations on the topic, and that the results of these future new studies will be able to shed the needed light.

Acknowledgement: Abdel Jaber M, Benini C, Boner A, Bortolotti R, Brigo M, Catalano A, Ferlin A, Girasole G, Idolazzi L, Lello S, Maestri E, Martinis $F$, Muratore M, Olivari F, Peroni D, Romagnoli E, Ruggiero C, Saviola G, Sella S, Strappini M, Silveri $F$, Vantaggiato $E$, Venturin A, Zuccaro C.

Disclosure of Interests: Alessandro Giollo: None declared, Ombretta Viapiana Speakers bureau: Novartis, Abbvie, Eli-Lilly, Sanofi Genzyme, Angelo Fassio Speakers bureau: Abiogen Pharma, Francesco Bertoldo: None declared, Vania Teresa Braga: None declared, Maria Luisa Brandi: None declared, Stefano Calvieri: None declared, Luisella Cianferotti Speakers bureau: Abiogen Pharma, Bruno Farmaceutici, Shire, Annamaria Colao: None declared, Patrizia D'Amelio: None declared, Giovanni Mario D'Avola: None declared, Luca Degli Esposti: None declared, Bruno Frediani: None declared, Sandro Giannini: None declared, Andrea Giusti Grant/research support from: Abiogen Pharma, Consultant for: EffRx, Speakers bureau: Abiogen Pharma, Eli Lilly, AMGEN, Andrea Giustina: None declared, Stefano Gonnelli: None declared, Nazzarena Malavolta: None declared, Claudio Marcocci Grant/research support from: Shire, Speakers bureau: Shire and AbiogenPharma, Salvatore Minisola: None declared, Nicola Napoli: None declared, Ranuccio Nuti: None declared, Giovanni Passeri Grant/ research support from: Abiogen Pharma and Chiesi Farmaceutici, Speakers bureau: Abiogen Pharma and Chiesi Farmaceutici, Maurizio Rossini: None declared, Luigi Sinigaglia: None declared, Francesco Vierucci: None declared, Davide Gatti Speakers bureau: Abiogen, Amgen, Janssen-Cilag, Mundipharma, Pfeizer

DOI: 10.1136/annrheumdis-2019-eular.3492

\section{AB0832 \\ VERTEBRAL PAIN AND PHYSICAL PERFORMANCE INDICES IN POSTMENOPAUSAL WOMEN WITH VERTEBRAL FRACTURES DEPENDING ON PRESENCE OF OBESITY}

Nataliia Grygorieva, Vladyslav Povoroznyuk. Institute of Gerontology named after D. F. Chebotarev NAMS of Ukraine, Kyiv, Ukraine

Background: Vertebral fractures (VFs) are important osteoporotic fractures which manifest increased morbidity and mortality; however, their clinical features usually differ. Obesity is one of the important parameters of risk of osteoporotic fractures and vertebral pain syndrome.

Objectives: The aim of the research was to study the indices of verte bral pain (VP) and physical performance (PP) in postmenopausal women with VFs depending on presence of obesity.

Methods: We examined 87 females aged 50-89 years old with VFs in thoracic and/or lumbar spine which were divided into 3 groups: I patients with normal weight $(\mathrm{NW})$, according to $\mathrm{WHO}$ criteria, $\mathrm{n}=32$; I women with overweight $(\mathrm{OW}), \mathrm{n}=37$; III - females with obesity (OB), $\mathrm{n}=18$. The parameters of $V P$ in thoracic and/or lumbar spine were meas ured by 11-component visual analog scale (VAS), the indices of PP using static and dynamic functional tests (Thomayer, Schober tests, chest excursion, lateral trunk lean, 3-, 4-, 15-meter tests, "stand up from the chair", static balancing). Bone mineral density (BMD) was measured by DXA (Lunar, Prodigy).

Results: We have found the significantly higher parameters of BMD of femoral neck and lumbar spine in women with VFs and OB compared to females with NW. However, we did not establish any reliable differences of VP neither in thoracic nor in lumbar spine depending on obesity presence. Also, we did not reveal the significant differences of most parameters of PP, except for the indices of chest excursion (mean parameter of the inhalation and exhalation) which were reliably higher in patients with $\mathrm{OB}$.

Conclusion: In conclusion, the indices of VP and PP do not differ in postmenopausal women depending on obesity presence, except for chest excursion that should be taken into account in rehabilitation programs for females with VFs.

Disclosure of Interests: None declared

DOI: 10.1136/annrheumdis-2019-eular.8264

\section{AB0833 BONE TURNOVER MARKERS - DO THEY HAVE A ROLE AS PREDICTORS OF MORTALITY AND NEW FRACTURE IN PATIENTS WITH FRAGILITY HIP FRACTURE?}

Miguel Guerra ${ }^{1}$, Sara Ganhão², Francisca Aguiar², Raquel Ferreira²,

Teresa Martins-Rocha ${ }^{2}$, Ana Filipa Águeda ${ }^{3}$, Georgina Terroso ${ }^{2}$, Carlos Vaz ${ }^{2,4}$ Lúcia Costa ${ }^{2} .{ }^{1}$ Centro Hospitalar de Vila Nova de Gaia/Espinho, Department of Rheumatology, Vila Nova de Gaia, Portugal; ${ }^{2}$ Centro Hospitalar e Universitário de São João, Department of Rheumatology, Oporto, Portugal; ${ }^{3}$ Centro Hospitalar do Baixo Vouga, Department of Rheumatology, Aveiro, Portugal; ${ }^{4}$ Oporto University, Faculty of Medicine, Oporto, Portugal

Background: In Osteoporosis (OP), bone turnover markers (BTM) are potential monitors of drug adherence/efficacy as well as predictors of bone loss and fracture risk. However, without solid evidence, international guidelines still do not recommend their systematic measurement to assist treatment decision and follow-up.

Objectives: To evaluate the predictive value of baseline BTM (beta crosslaps - bCL; osteocalcin - OC) in the outcome (death and/or new fracture) of patients that suffered a fragility hip fracture (FHF).

Methods: Patients referred to a Fracture Liaison Service from March 2015 until March 2017 with a FHF were considered for this study. Clini$\mathrm{cal} /$ demographic variables were collected, including: age at time of fracture, sex, serum $\mathrm{OC}$ and serum bCL at baseline and outcome (death, new fracture, lost to follow-up) until January 2018. Cox regression analysis was used to calculate hazard ratios $(H R)$ for values of $O C$ and $b C L$; $\mathrm{p}<=0.05$ was considered statistically significant.

Results: From a total of 522 patients, 218 presented a baseline measurement of $\mathrm{OC}$ and/or bCL and were included for analysis. Table 1 summarizes clinical and demographic characteristics of the sample. Twenty seven patients died (median days until death $=457$, $\min 160$, max 1049) and 18 had a new fracture (median days until refracture 343.5 , min 30 , max 835); 129 patients maintained follow-up. Median serum bCL was 